Background: Recreational physical activity has been consistently associated with lower breast cancer risk, but there is a need to study the intensity and duration of activity that are critical to reduce the risk. The aim of this study was to examine the influence of moderate and vigorous intensity of recreational physical activity performed at different age periods on breast cancer risk.

Material and methods: The case-control study included 858 women with histological confirmation of invasive breast cancer and 1085 women free of any cancer diagnosis, residents of the region of Western Pomerania, aged 28-79 years. The frequency, duration and intensity of lifetime household, occupational and recreational physical activity, sociodemographic characteristics, reproductive factors, family history of breast cancer, current weight and height, and lifestyle habits were measured using a selfadministered questionnaire. Unconditional logistic regression analyses were applied to estimate odds ratios (ORs) and $95 \%$ confidence intervals (Cls). The risk estimates were controlled for potential risk factors and lifetime household and occupational activities.

Results: We found a risk reduction for recreational activity done early in life (age periods $14-20,21-34,35-50$ years), particularly at ages 14-20 and 21-34 years, regardless of intensity. Active women engaging in more than 4.5 hours per week of moderate activity during ages 14-20 years had, on average, a 36\% lower risk $(\mathrm{OR}=0.64,95 \% \mathrm{Cl}: 0.45-0.89)$ than women who were never or rarely active. For the women who reported 4.5 hours per week of vigorous activity during this period we found about $64 \%$ risk reduction $(\mathrm{OR}=0.36,95 \% \mathrm{Cl}: 0.26-0.51)$. For the period after 50 years of age, recreational activity of moderate or vigorous intensity was not significantly associated with the risk.

Conclusion: Recreational physical activity of moderate or vigorous intensity done during adolescence, early and middle adulthood, particularly at ages $14-20$ and $21-34$ years, is associated with significantly decreased breast cancer risk.

Key words: breast cancer, physical activity, prevention, age, intensity, case-control study.

\section{Intensity of recreational physical activity in different life periods in relation to breast cancer among women in the region of Western Pomerania}

\author{
Joanna Kruk
}

Faculty of Physical Culture and Health Promotion, University of Szczecin, Poland

\section{Introduction}

Breast cancer is recognized as the most frequently diagnosed cancer among women worldwide, accounting for 1,383 500 of the total new cancer cases and 458400 of the total cancer deaths in 2008 [1]. Of these, 692200 (50\%) of the cases and 189500 deaths (27.4\%) occurred in developed countries. Poland is one of the countries with a medium incidence rate; in 2009 it was 15752 new cancer cases and 5362 cancer deaths in 2010 [2]. The development of breast cancer is regarded as a multifactorial process, which means that the direct causes are unknown. However, most epidemiological findings, laboratory animal and clinical studies have recognized risk factors that increase the likelihood of breast cancer developing. Established risk factors include racial group and ethnic country of birth, old age, family disposition, hormonal factors, mammary lesions, exogenous estrogens, obesity, and sedentary lifestyle $[3,4]$. The effect of physical activity, especially recreational, on breast cancer risk was reported by numerous epidemiological studies and analyzed in systematic reviews [5-7]. A recently published review of the epidemiologic evidence reported a $25 \%$ average statistically significant risk reduction among physically active women compared to the least active [7]. The association was the strongest for recreational physical activity, ranging from $23 \%$ to $65 \%$ in findings from case-control studies and from $21 \%$ to $39 \%$ from cohort studies [5]. However, inconsistent findings have been reported regarding a few aspects of physical activity. So far, the time periods in life in which physical activity is the most protective as well as the optimal dose (intensity, duration, frequency of activity) are unknown. Some authors have presented findings indicating that physical activity of vigorous intensity had the greatest impact on breast cancer [8-10], others that moderate to vigorous activity performed regularly did so [11]. Some studies observed no association between intensity of physical activity and the risk of breast cancer $[12,13]$. An expert panel of WCRF and AICR has estimated that physical activity plays a probable preventive role against breast cancer in postmenopausal women, while in premenopausal women the evidence is weaker - limited-suggestive [14]. Estimation of the impact of physical activity on the breast cancer risk is important regarding the public health recommendation and biological mechanisms. Several hypothesized mechanisms relating physical activity and the risk of breast cancer have been proposed in the epidemiologic literature [for review see, e.g. 7, 15-17]. The most frequently reported implicate: reduction of lifetime exposure to sex steroid hormones [18-21], reduction of exposure to insulin and insulin-like growth factor 1 (IGF-1) [22], increase of circulating sex hormone binding globulin (SHBG) and protein binding of IGF-1 [16]. In addition, regular physical activity with mod- 
erate intensity is considered as a modulator of inflammation $[16,23]$, enhances the immune system, and increases antioxidant enzyme levels in order to prevent oxidative stress caused by reactive oxygen species and free radicals [24]. Moreover, physical activity of vigorous intensity is a mediator for the energy balance through reduction of body weight and body fat loss.

The study was designed specifically to estimate the association between recreational physical activity of varying intensity with special emphasis on the potential effect of time periods (14-20, 21-34, 35-50, > 50 years) in a woman's life.

\section{Material and methods}

This case-control study was conducted between January 2003 and May 2007. The study received approval of the Ethics Committee of the Pomeranian Medical Academy in accordance with the Polish Department of Health and Human Services, and all study participants provided written informed consent before the interview. Cases were women aged 2879 years diagnosed with histologically confirmed invasive breast cancer residing in the region of Western Pomerania. They were identified from the Szczecin Cancer Registry and selected using a random number generator.

Female controls were randomly recruited among the outpatients from ambulatories, clinics, and hospitals located in the region of Western Pomerania and were free of any cancer diagnosis. Controls were frequency matched to the cases by age within 5-year groups and by place of residence. During the study period, 2409 cases were asked to participate in the study, 1187 cases agreed to participate in the study, and 881 of them completed the questionnaire, sent in the study package. Similarly, of the 1615 controls potentially eligible within the age range, 1189 agreed to receive the questionnaire, but 1121 of them completed and returned it. After verification, the final set included 858 (49.3\%) cases and 1085 (67.2\%) controls. Respondents reported their demographic characteristics, menstrual and reproductive histories, family history of cancer, personal history of breast disease (cases), use of oral contraceptives (OCP), postmenopausal hormonal replacement therapy (HRT) use, habits, and anthropometric measurements. For cases, all data obtained were currently as of the date of cancer diagnosis, and controls were assigned a comparable date. Detailed information on lifetime physical activity from all sources (household, occupational, and recreational) was assessed for each woman using a questionnaire modeled on those of Kriska et al. [25] and Friedenreich et al. [26] to allow for self-administration. The number of years, months per year, weeks per month, days per week, and hours per day that each activity was performed were reported by study participants. Recreational physical activity was reported separately for four age intervals: ages $14-20,21-34,35-50$, and over 50 years. For each age period, women reported their participation in each of 43 different sports and exercise activities up to the reference year (the year before diagnosis for the cases and the year before selection for the study for controls). Only regular participation in sports or exercise of at least one hour a week for at least 4 months per year was included in the analysis. Quantitative analysis of intensity of the activity was estimated using a specific metabolic equivalent (MET) score defined as "the ratio of the metabolic rate associated with a specific activity to the resting metabolic rate", abstracted from the Compendium of Physical Activities [27]. Examples of intensity codes used in the classification of physical activity levels are as follows: swimming - 6 MET, running - 7.5 MET. Intensity of physical activity was categorized as follows: low intensity (activities under 3 METs), moderate (activities between 3 and 6 METs), and vigorous (above 6 METs). This categorization is commonly used in the subject literature [11]. The variables estimated in this analysis were average hours/week per year spent in recreational activity during considered intervals of age, calculated using the formulae given by Friedenreich et al. [26]. Variables were categorized into quartiles according to the distribution of the variables among controls. Odds ratios (ORs) and corresponding 95\% confidence intervals ( $\mathrm{Cls})$, as a measure of relative risk of breast cancer, were calculated by using unconditional logistic regression and a full assessment of confounding. Tests for a linear trend across ordinal values of categorical variables were conducted by entering physical activity as the continuous variable in statistical models by using a Wald $\chi^{2}$ value. All the analyses were done using the statistical package STATISTICA 98 (StatSoft Polska, Kraków, Poland), and a $p$ value less than 0.05 was considered statistically significant. Odds ratios were adjusted for potential confounders selected a priori: family history of breast cancer in mother, sisters, or daughters (yes, no), education (elementary school, middle school, high school, academy, and above), place of residence (urban/rural), family income average over past 10 years (low, middle, high), marital status (never married, married, widowed/divorced), body mass index (BMI) $(\leq 22.5,22.6-<25.0$, $\left.25-<30, \geq 30 / \mathrm{kg} \mathrm{m}^{2}\right)$, age at menarche $(\leq 12,13, \geq 14)$, age at first childbirth $(<22,22-29, \geq 30)$, number of pregnancies $(0,1,2, \geq 3)$, months of breast feeding $(0,<6, \geq 6)$, use of oral contraceptives (never, ever), age at menopause $(<50$, $50-54, \geq 55$ years), postmenopausal hormone replacement therapy (HRT) use (never, ever), regular self-examination of breast (no, yes), stress experience (no, yes), smoking status (never smokers, smokers $<10$ cigarettes/day, $\geq 10$ cigarettes/day), passive smoking (smoking husband: $<20$ cigarettes/day, $\geq 20$ cigarettes/day), alcohol consumption (never, $\leq 1 \mathrm{drink} /$ week, 2-4 drinks/week, $\geq 5$ drinks/week), red meat consumption (< 1 serving/week, 1-2 servings/week, 3-4 servings/week, $\geq 5$ servings/week), animal fat consumption ( $\leq 2$ times/week, $\geq 3$ times/week), consumption of vegetables, fruits in tertiles: very rarely ( $\leq 2$ servings/week), rarely (3-4 servings/week), and frequently ( $\geq 5$ servings/week, every day, several times daily), screening mammography or ultrasound examination of breast within past 2 years (no, yes). In addition, models were adjusted for household and occupational physical activity and mutually adjusted for other intensity during the same age period. Final models were adjusted for variables that were found to influence the quality of the model fit, and were statistically significant in the multivariate analyses; they are reported in legends of tables. The selection of variables was carried out using the $\chi^{2}$ test of maximum reliability. 


\section{Results}

Characteristics of case patients and control subjects, and association of lifestyle and other risk factors with the risk of breast cancer have been previously reported [28]. Briefly, cases did not differ from controls with respect to average age, age at menarche, age at first birth, parity, age at menopause, marital status, frequency of alcohol intake, and HRT use. Compared with controls, cases were less educated, had a higher BMI, reported shorter duration of breast-feeding, were more likely to have had a family history of breast cancer, to be active or passive cigarette smokers, users of oral contraceptive pills, and more frequently experienced psychological stress. The average annual number of hours per week of recreational, household, and occupational physical activity reported by cases over their lifetimes was lower compared with controls. Cases and controls spent a similarly short time in low intensity (<3 METs) recreational physical activity (about 0.03 hours/week). The difference in recreational physical activity levels of moderate intensity between cases and controls by age periods are shown in Table 1 . The statistically significant lowest relative risks observed occurred for activity performed between 14 and 20 years, for which the multivariable-adjusted OR was 0.59 (95\% Cl: 0.44-0.88) for activity duration 1.7-4.5 hours/week versus never/rarely. A longer term of moderate physical activity did not cause stronger reduction. It is worth noting a highly significant trend of decreas- ing risk with increasing duration of activity. Breast cancer risks were also reduced for women in the third tertile of activity during the periods $21-34$ and $35-50$ years. The tests for a linear trend were significant, but the decreased ORs were significant in the age-adjusted models and for women in the third category of activity (0.8-2.4 and 0.75-2.5 hours/week, respectively) in the multivariable-adjusted models. Recreational physical activity at age over 50 years was not associated with a risk decrease, though the risk was significantly decreased for the highest quartile of activity in an age-adjusted model.

The repeated analyses for this type of activity of vigorous intensity are presented in Table 2. Statistically significant risk reductions were found for activities done during the periods 14-20, 21-34, and 35-50 years in both the age-adjusted and multivariable-adjusted models, similarly as in the case of moderate intensity. The greatest risk reductions for vigorous activity were observed among women who engaged in activity during the periods 14-20 and 21-34 years. Women who were in the highest quartiles of assigned vigorous intensity $(>4.5$ hours/week and $>1.8$ hours/week) compared with those who reported never/rarely performing vigorous activity experienced $64 \%$ and $54 \%$ reduction for activity done during the periods 14-20 and 21-34 years (ORs of 0.36 and 0.46 , respectively) ( $p$ for trends $<0.0001$ ). Women who were in the top tertile of activity between 35 and 50 years had an OR of 0.61 ( $95 \% \mathrm{Cl}$ :

Table 1. Odds ratios (OR) and 95\% confidence intervals $(\mathrm{Cl})$ for breast cancer in relation to recreational physical activity of moderate intensity

\begin{tabular}{|c|c|c|c|c|}
\hline $\begin{array}{l}\text { Age period/risk factor } \\
\text { (hours/week per year) }\end{array}$ & Cases & Controls & $\begin{array}{l}\text { Age adjusted } \\
\mathrm{OR}^{*}(95 \% \mathrm{Cl})\end{array}$ & $\begin{array}{l}\text { Multivariable adjusted } \\
\qquad \mathrm{OR}^{\star \star}(95 \% \mathrm{Cl})\end{array}$ \\
\hline \multicolumn{5}{|l|}{ 14-20 years } \\
\hline $\begin{array}{l}\text { never/rarely } \\
<1.7 \\
1.7-4.5 \\
>4.5 \\
p \text { for trend }\end{array}$ & $\begin{array}{l}489 \\
169 \\
118 \\
82\end{array}$ & $\begin{array}{l}466 \\
193 \\
216 \\
210\end{array}$ & $\begin{array}{c}1.00 \\
0.85(0.67-1.09) \\
0.53(0.41-0.68) \\
0.37(0.28-0.49) \\
<0.0001\end{array}$ & $\begin{array}{c}1.00 \\
0.86(0.64-1.14) \\
0.59(0.44-0.80) \\
0.64(0.45-0.89) \\
<0.00001\end{array}$ \\
\hline \multicolumn{5}{|l|}{ 21-34 years } \\
\hline $\begin{array}{l}\text { never/rarely } \\
<0.8 \\
0.8-2.4 \\
>2.4 \\
p \text { for trend }\end{array}$ & $\begin{array}{c}577 \\
130 \\
70 \\
81\end{array}$ & $\begin{array}{l}599 \\
163 \\
167 \\
156\end{array}$ & $\begin{array}{c}1.00 \\
0.84(0.65-1.09) \\
0.44(0.32-0.62) \\
0.54(0.40-0.72) \\
<0.0001\end{array}$ & $\begin{array}{c}1.00 \\
1.02(0.74-1.39) \\
0.54(0.38-0.75) \\
0.84(0.60-1.19) \\
<0.0051\end{array}$ \\
\hline \multicolumn{5}{|l|}{$35-50$ years } \\
\hline $\begin{array}{l}\text { never/rarely } \\
<0.75 \\
0.75-2.5 \\
>2.5 \\
p \text { for trend }\end{array}$ & $\begin{array}{l}554 \\
118 \\
96 \\
90\end{array}$ & $\begin{array}{l}596 \\
161 \\
167 \\
161\end{array}$ & $\begin{array}{c}1.00 \\
0.80(0.61-1.05) \\
0.62(0.46-0.84) \\
0.60(0.45-0.79) \\
<0.0001\end{array}$ & $\begin{array}{c}1.00 \\
0.86(0.62-1.17) \\
0.71(0.52-0.98) \\
0.87(0.62-1.20) \\
<0.037\end{array}$ \\
\hline \multicolumn{5}{|l|}{$>50$ years } \\
\hline $\begin{array}{l}\text { never/rarely } \\
<0.8 \\
0.8-2.9 \\
>2.9 \\
p \text { for trend }\end{array}$ & $\begin{array}{c}717 \\
51 \\
48 \\
42\end{array}$ & $\begin{array}{c}872 \\
71 \\
67 \\
75\end{array}$ & $\begin{array}{c}1.00 \\
0.82(0.56-1.20) \\
0.83(0.56-1.23) \\
0.63(0.42-0.94) \\
0.015\end{array}$ & $\begin{array}{c}1.00 \\
0.85(0.54-1.33) \\
0.92(0.59-1.43) \\
0.80(0.51-1.25) \\
<0.40\end{array}$ \\
\hline
\end{tabular}

smoking, intake of vitamins, vigorous recreational physical activity, household and occupational physical activity. 
Table 2. Odds ratios $(\mathrm{OR})$ and $95 \%$ confidence intervals $(\mathrm{Cl})$ for breast cancer in relation to recreational physical activity of vigorous intensity

\begin{tabular}{|c|c|c|c|c|}
\hline $\begin{array}{l}\text { Age period/risk factor } \\
\text { (hours/week per year) }\end{array}$ & Cases & Controls & $\begin{array}{l}\text { Age adjusted } \\
\mathrm{OR}^{*}(95 \% \mathrm{Cl})\end{array}$ & $\begin{array}{c}\text { Multivariable adjusted } \\
\qquad \mathrm{OR}^{\star *}(95 \% \mathrm{Cl})\end{array}$ \\
\hline \multicolumn{5}{|l|}{$14-20$ years } \\
\hline $\begin{array}{l}\text { never/rarely } \\
<1.7 \\
1.7-4.5 \\
>4.5 \\
p \text { for trend }\end{array}$ & $\begin{array}{c}490 \\
189 \\
112 \\
67\end{array}$ & $\begin{array}{l}442 \\
214 \\
217 \\
212\end{array}$ & $\begin{array}{c}1.00 \\
0.82(0.65-1.04) \\
0.47(0.36-0.61) \\
0.28(0.20-0.38) \\
<0.0001\end{array}$ & $\begin{array}{c}1.00 \\
0.85(0.65-1.12) \\
0.56(0.41-0.75) \\
0.36(0.26-0.51) \\
<0.0001\end{array}$ \\
\hline \multicolumn{5}{|l|}{$21-34$ years } \\
\hline $\begin{array}{l}\text { never/rarely } \\
<0.56 \\
0.56-1.8 \\
>1.8 \\
p \text { for trend }\end{array}$ & $\begin{array}{r}628 \\
107 \\
64 \\
59\end{array}$ & $\begin{array}{l}617 \\
155 \\
157 \\
156\end{array}$ & $\begin{array}{c}1.00 \\
0.69(0.52-0.90) \\
0.40(0.29-0.55) \\
0.40(0.26-0.50) \\
<0.0001\end{array}$ & $\begin{array}{c}1.00 \\
0.79(0.57-1.08) \\
0.47(0.33-0.77) \\
0.46(0.32-0.66) \\
<0.0001\end{array}$ \\
\hline \multicolumn{5}{|l|}{$35-50$ years } \\
\hline $\begin{array}{l}\text { never/rarely } \\
<0.49 \\
0.49-1.74 \\
>1.74 \\
p \text { for trend }\end{array}$ & $\begin{array}{c}619 \\
98 \\
69 \\
72\end{array}$ & $\begin{array}{l}680 \\
136 \\
136 \\
133\end{array}$ & $\begin{array}{c}1.00 \\
0.80(0.60-1.06) \\
0.56(0.41-0.76) \\
0.58(0.43-0.80) \\
<0.0001\end{array}$ & $\begin{array}{c}1.00 \\
0.79(0.57-1.09) \\
0.78(0.55-1.11) \\
0.61(0.43-0.86) \\
0.012\end{array}$ \\
\hline \multicolumn{5}{|l|}{$>50$ years } \\
\hline $\begin{array}{l}\text { never/rarely } \\
<0.52 \\
0.52-1.74 \\
>1.74 \\
p \text { for trend }\end{array}$ & $\begin{array}{c}767 \\
35 \\
31 \\
25\end{array}$ & $\begin{array}{c}932 \\
46 \\
54 \\
53\end{array}$ & $\begin{array}{c}1.00 \\
0.89(0.56-1.42) \\
0.68(0.43-1.08) \\
0.54(0.33-0.89) \\
0.0031\end{array}$ & $\begin{array}{c}1.00 \\
0.88(0.52-1.49) \\
0.76(0.45-1.28) \\
0.69(0.39-1.22) \\
0.087\end{array}$ \\
\hline
\end{tabular}

$0.43-0.86)$ and the linear trend was also statistically significant $(p=0.012)$. For the period after 50 years of age recreational physical activity of vigorous intensity was not significantly associated with breast cancer risk ( $p=0.087)$; however, the risk was suggestively decreased among the women reporting at least 0.52 hours/week of vigorous activity. As can be seen from Tables 1 and 2, the age- and multivariableadjusted OR estimates for association of considered levels of recreational activity with breast cancer incidence are often different. Risk reductions were greater in age-adjusted models. After multivariable adjustment and mutually adjusting for other categories of physical activity evaluated in the questionnaire the risks were attenuated.

\section{Discussion}

Data analysis shows that recreational physical activity was strongly associated with the reduced risk for breast cancer for activity during youth (14-20 years), 21-34 years and between 35 and 50 years of age. Statistically significant decreases in the risk occurred among women engaged in recreational activity, regardless of assigned intensity (moderate or vigorous). However, the most marked and consistent risk reductions were observed for activities of vigorous intensity during all the above-mentioned age periods. These data show that moderate recreational activity may be sufficient to protect a women against breast carcinogenesis and are consistent with most previous research [9, 13, 29-31]. The analysis by Patel et al. [31] revealed, however, that moderate intensity of activity may be sufficient to reduce the risk of breast cancer in women with lower levels of baseline circulating estrogen. Knowledge that moderate physical activity is sufficient to reduce the risk of breast cancer may be particularly important for public health, as women engage most frequently in activities of lower energy expenditure. Very recent data on physical activity levels in 15 countries of Europe, including Poland, show that only $12.2 \%$ of Polish respondents reported a high level of sport and recreational activity and half of the respondents reported very low or no activity [32]. Tehard and co-workers have observed that almost twice as long time of participation in moderate recreational activity is required to obtain a similar risk reduction as participation in high-intensity activity. The authors found a 38\% reduction of the risk for women who undertook $\geq 5$ hours per week of vigorous recreational activity. Although the mechanisms of the effect of physical activity on the risk of breast cancer are not yet well understood, the findings reported here are consistent with those of two previous investigations [20,33] that found decreased concentrations of estradiol and its metabolites induced by moderate and vigorous activity. In addition, the study of Di Petro et al. [34] suggests that physical activity of vigorous intensity enhances insulin sensitivity.

To our knowledge, only a few studies [8, 35-37] have analyzed both the intensity level and the period of life of recreational activity in relation to the risk of breast cancer. For 
example, Dallal et al. [8] observed about 20\% reduced risk of invasive breast cancer and a 31\% reduction in women with an incident carcinoma in situ, who reported $>5$ hours/week of vigorous recreational activity at ages $25-34$ and 35-44 years. The authors also reported a decrease in risk of noninvasive breast cancer linked to vigorous activity at ages 18-24 years, and a lack of reduction in risk for both moderate and vigorous activity performed at ages $45-54$ years. In turn, Pepłońska et al. [36] in a case-control study of Polish women reported a statistically significant decreased risk of breast cancer for combined moderate and vigorous intensity recreational physical activity (MET $\geq 4.5)$ at ages 20-24, 25-29, 30-34, 35-39, 40s, 50s, and 60s among participants achieving at least 12.4 MET-hours/week for these periods except at age 60-69. We found the greatest risk decrease for recreational activity in ages 14-20 years regardless of the intensity. The greatest benefit of recreational physical activity observed in this study during youth, in the time period when increases in sex hormones and accompanying changes in mammary glands occurred, is in accordance with hypothesized hormone-related mechanisms relating physical activity to breast cancer risk. Physical activity can delay menarche and/or change menstrual cycles, thereby reducing lifetime exposure to the mitogenic effects of endogenous estrogens [38]. Other studies have also found a significant decrease in breast cancer risk among women regularly engaged in recreational activity at a young age [reviewed in 5 and 39]. Risk reductions were also observed for activity performed in early adulthood and middle adulthood similarly as in our study $[8,9,36]$. In contrast to a study carried out by Pepłońska et al. [36], the study by Lee et al. [35] and our study found no significant decrease in breast cancer risk for activity after 50 years of age in multivariable models. In this context it is interesting to note that physical inactivity is one of the well-established risk factors for breast cancer and other civilization diseases that can be modified through behavior changes. In addition to the primary preventive role of regular moderate-vigorous physical activity of some cancers, there is growing interest in its use in the treatment and rehabilitation of patients with cancer. Physical activity may reduce fatigue and depression, which are most prevalent among women after mastectomy [40-42]. A role of physical activity in quality of life of women after mastectomy as a means of improving their physical and mental health is beneficial. In addition, regular lifetime physical activity as a main component of lifestyle can also be considered as a helpful factor to cope with the difficulties resulting from the long-lasting illness, e.g. to increase the level of sense of coherence - a crucial factor that allows patients to return to their everyday life [43].

This study should be interpreted within the context of certain limitations, as in most case-control studies, but has several advantages as well.

The most important limitation is that we relied on selfreported physical activity measures, and the overall response rate was lower among cases than among controls who participated in the study. To address this issue of selection bias, the participants were compared with a sample of Polish women aged 20 to 74 years who participated in the case- control study evaluating risk factors by breast cancer tumor characteristics [3] and the women surveyed by the Chief Central Statistical Office (GUS) as the Polish Population Health Survey [44], on several medical, lifestyle and social characteristics. The participants were found to have several very similar characteristics; therefore despite the relatively low response rates for the cases, the examined group was representative of the base population of women in the region of Western Pomerania. In addition, the strong breast cancer risk reduction observed for vigorous physical activity and a little weaker for moderate activity and consistency with the literature data argue against any strong selection bias. Each method of assessing physical activity may introduce a misclassification bias in the analyses. This limitation was addressed by assessing various types of physical activity, by recording frequency, duration and intensity of each reported activity. However, concerning this point, any misclassification is not likely to be differential because there is still limited awareness of the preventive role of physical activity against breast cancer. Another limitation of this study is that we asked participants to report detailed lifetime physical activity patterns. We tried to reduce the recall bias by collecting information about recreational physical activity performed at four time periods in a woman's life. An additional limitation of this study is a lack of adjustment for energy intake, likely as in most studies.

Strong points of this investigation include a large sample size, histological confirmation of breast cancer, comprehensive measurement of physical activity, and detailed information available on potential confounders.

In conclusion, this study of recreational physical activity and breast cancer found the preventive effect of activity among women engaged in moderate or vigorous activities during adolescence and early and middle adulthood. Although the intensity of the reported recreational physical activity was not a major contributor to the risk reduction but its duration, the greatest risk reduction was observed for vigorous activities. Of the four periods of activity assessed in this paper, the strongest decrease in risk of breast cancer could be achieved by engaging in recreational activity during adolescence and early adulthood.

The authors declare no conflict of interest.

\section{References}

1. Jemal A, Bray F, Center MM, Ferlay J, Ward E, Forman D. Global cancer statistics. CA Cancer J Clin 2011; 61: 69-90.

2. Krajowa Baza Danych Nowotworowych. Raporty na podstawie danych Centrum Onkologii. http://www.onkologia.org.pl z dnia 28.09.2012

3. Garcia-Closas M, Brinton LA, Lissowska J, et al. Established breast cancer risk factors by clinically important tumour characteristics. Br J Cancer 2006; 95: 123-9.

4. Hulka BS, Moorman PG. Breast cancer: hormones and other risk factors. Maturitas 2001; 38: 103-6.

5. Monninkhof EM, Elias SG, Vlems FA, et al. Physical activity and breast cancer: a systematic review. Epidemiol 2007; 18: 137-57.

6. Friedenreich CM, Neilson HK, Lynch BM. State of the epidemiological evidence on physical activity and cancer prevention. Eur J Cancer 2010; 46: 2593-604. 
7. Friedenreich CM. Physical activity and breast cancer: review of the epidemiologic evidence and biological mechanisms. In: Clinical Cancer. Prevention, Recent results in Cancer Research. Senn HJ, Otto F (eds.). Springer-Verlag, Berlin - Heidenberg 2010.

8. Dallal CM, Sullivan-Halley J, Ross RK, et al. Long-term recreational physical activity and risk of invasive and in situ breast cancer: the California teachers study. Arch Intern Med 2007; 167: 408-15.

9. Tehard B, Friedenreich CM, Oppert JM, Clavel-Chapelon F. Effect of physical activity on women at increased risk of breast cancer: results from the E3N cohort study. Cancer Epidemiol Biomarkers Prev 2006; 15: 57-64.

10. Leitzmann MF, Moore SC, Peters TM, et al. Prospective study of physical activity and risk of postmenopausal breast cancer. Breast Can cer Research 2008; 10R92doi:10.1186/brc 2190.

11. Friedenreich CM, Courneya KS, Bryant HE. Relation between intensity of physical activity and breast cancer risk reduction. Med Sci Sports Exerc 2001; 33: 1538-45.

12. Maruti SS, Willett WC, Feskanich D, Rosner B, Colditz GA. A prospective study of age specific physical activity and premenopausal breast cancer. J Natl Cancer Inst 2008; 100: 728-37.

13. John EM, Horn-Ross PL, Koo J. Lifetime physical activity and breast cancer risk in a multiethnic population: the San Francisco Bay area breast cancer study. Cancer Epidemiol Biomarkers Prev 2003; 12: 1143-52.

14. World Cancer Research Fund (WCRF)/American Institute for Cancer Research (AICR). Food, Nutrition, Physical Activity, and the Prevention of Cancer: a Global Perspective. The Panel's judgements Washington, DC: AICR 2007; 8-14, 200

15. McTiernan A. Mechanisms linking physical activity with cancer. Nat Rev Cancer 2008; 8: 205-11.

16. Neilson HK, Friedenreich CM, Brockton NT, Millikan RC. Physical activity and postmenopausal breast cancer: proposed biological mech anisms and areas for future research. Cancer Epidemiol Biomarkers Prev 2009; 18: 11-27.

17. Thompson HJ, Jiang W, Zhu Z. Candidate mechanisms accounting for effects of physical activity on breast carcinogenesis. IUBMB Life 2009; 6: 895-901.

18. Coyle YM. Physical activity as a negative modulator of estrogeninduced breast cancer. Cancer Causes Control 2008; 19: 1021.

19. McTiernan A. Physical activity effects on sex hormones. In: Cancer Prevention and Management through Exercise and Weight Control. McTiernan A (red.). CRC Taylor \& Francis 2006; pp. 121-30.

20. Jasieńska G, Ziomkiewicz A, Thune I, Lipson SF, Ellison PT. Habitual physical activity and estradiol levels in women of reproductive age. Eur J Cancer Prev 2006; 15: 439-45.

21. Fuhrman BJ, Schairer C, Gail MH et al. Estrogen metabolism and risk of breast cancer in postmenopausal women. J Natl Cancer Inst 2012 104: 326-39.

22. Borghouts LB, Keizer HA. Exercise and insulin sensitivity: a review. Int J Sports Med 2000; 21: 1-12.

23. Wetmore CM, Ulrich CM. Mechanisms associated physical activi ty with cancer incidence: exercise and immune function. In: Cancer Prevention and Management through Exercise and Weight Control. McTiernan A (ed.). CRC Taylor \& Francis 2006; 157-75.

24. Rundle A. Molecular epidemiology of physical activity and cancer Cancer Epidemiol Biomarkers Prev 2005; 14: 227-36.

25. Kriska AM, Knowler WC, LaPorte RE, et al. Development of ques tionnaire to examine relationship of physical activity and diabetes in Pima Indians. Diabetes Care 1990; 13: 401-11.

26. Friedenreich CM, Courneya KS, Bryant HE. The lifetime total phys ical activity questionnaire: development and reliability. Med Sci Sports Exerc 1998; 30: 266-74.

27. Ainsworth BE, Haskell WL, Leon AS, Jacobs DR, Jr, Montoye HJ, Sallis JF, Paffenbarger RS, Jr. Compendium of physical activities: classification of energy costs of human physical activities. Med Sci Sports Exerc 1993; 25: 71-80.

28. Kruk J. Association of lifestyle and other risk factors with breast cancer according to menopausal status: a case-control study in the region of Western Pomerania (Poland). Asian Pacific J Cancer Prev 2007 8: 513-24.

29. Young D, Bernstein L, Wu AH. Physical activity and breast cancer risk among Asian-American women in Los Angeles: a case-control study. Cancer 2003; 97: 2565-75.
30. Lahmann PH, Friedenreich C, Schuit AJ. Physical activity and breast cancer risk: The European prospective investigation into cancer and nutrition. Cancer Epidemiol Biomarkers Prev 2007; 16: 36-42.

31. Patel AU, Calle EE, Bernstein L. Wu AH, Tun MJ. Recreational physical activity and risk of postmenopausal breast cancer in a large cohort of US women. Cancer Cases Control 2003; 14: 519-29.

32. Piątkowska M. Self-rated physical activity level across Europe-Poland and other European countries. Biol Sport 2012; 29: 23-31.

33. Rockhill B, Willett WC, Hunter DJ, Manson JE, Hankinson SE, Graham A, Colditz MD. A prospective study of recreational physical activity and breast cancer risk. Arch Intern Med 1999; 159: 2290-6.

34. Di Pietro L, Dziura J, Yeckel CW, Neufer PD. Exercise and improved insulin sensitivity in older women: evidence of the enduring benefits of higher intensity training. J Appl Physiol 2006; 100: 142-9.

35. Lee IM, Cook NR, Rexrode KM, Buring JE. Lifetime physical activity and risk of breast cancer. Br J Cancer 2001; 85: 962-5.

36. Pepłońska B, Lissowska J, Hartman TJ, et al. Adulthood lifetime physical activity and breast cancer. Epidemiology 2008; 19: 226-36.

37. Peters TM, Moore SC, Gierach GL, Wareham NJ, Ekelund U, Hollenbeck AR, Schatzkin A, Leitzmann MF. Intensity and timing physical activity in relation to menopausal breast cancer risk: the prospective $\mathrm{NIH}$ AARP Diet and Health Study. BMC Cancer 2009; 1: 349.

38. Tworoger SS, Missmer SA, Eliassen AH, Barbieri R, Dowsett M, Hankinson S. Physical activity and inactivity in relation to sex hormone, prolactin and insulin-like growth factor concentrations in premenopausal women - exercise and premenopausal hormones. Cancer Causes Control 2007; 18: 743-52.

39. Friedenreich CM, Cust AE. Physical activity and breast cancer risk: impact of timing, type and dose of activity and population subgroup effects. Br J Sports Med 2008; 42: 636-47.

40. Golden Kreutz DM, Andersen L. Depressive symptoms after breast cancer surgery: relationships with global, cancer-related, and life event stress. Psychooncology 2004; 13: 211-20.

41. Rzepka K, Nowicki A. Zespół zmęczenia u chorych na raka piersi. Wspolczesna Onkologia 2010; 14: 321-5.

42. Kozela M, Stepaniak U, Pająk A. Membership in a breast cancer peersupport organization (Amazons Club) and depression. Contemporary Oncology 2011; 15: 55-8.

43. Kurowska K, Kaczorek B. Sense of coherence (SOC) and social support received by women after mastectomy. Contemporary Oncology 2011; 15: 124-9.

44. Główny Urząd Statystyczny (GUS). Stan zdrowia ludności Polski w 2004 r. GUS, Warszawa 2006

\section{Address for correspondence}

\section{dr hab. Joanna Kruk}

Faculty of Physical Culture and Health Promotion

University of Szczecin

ul. Piastów 40b/6

71-065 Szczecin

Poland

Submitted: $\quad 20.06 .2009$

Accepted: $\quad 20.09 .2012$ 